\title{
Research in surgery
}

\section{Pesquisa em cirurgia}

\author{
Aldo Cunha Medeiros, ECBC-RN¹.
}

W e must agree that research represents the backbone for the development of surgery. Research in surgery, developed by a multidisciplinary team of researchers and support team, focused on the prevention and relief of human suffering due to surgical disease. The way to achieve this vision is through the use of patient-centered outcome research. Patientcentered researchers use data critical evaluation to identify the best evidence to guide patient care in the real world. Researchers are interested in how various procedures influence the patient's health in terms of functional capacity and quality of life. Once best practices are identified, research surgeons or academic surgeons, whether in basic or clinical research, work with common sense to sooner or later make them a reality for all surgical patients.

However, the reality in our country is that incentives for research are scarce, one of the causes that makes the great majority of Brazilian surgeons exclusively dedicated to the care activity, both in public and private hospitals, university or do not. It must be recognized that in order to perform relevant, goodquality and scientifically-based research, it takes time, a lot of teamwork, and no financial return most of the time. Three magic words are essential for the activity of research: interest, appreciation for what one does and dedication.

\section{Developing the interest for research in surgery}

The interest in surgical research has been a decisive factor in the surgical advances observed over time, since it represents the key to the progress of surgical sciences. How to stimulate interest in research? This is the critical issue that needs to be answered in order to get the best possible participation. One must believe that mixing interest in research with the results coming from it shows the benefits of research in the surgical sciences and patient care. In addition, emphasizing the importance of the interest in scientific research in meetings of Surgery Services and in Brazilian and International Surgery Congresses represents the best way to position its prominence among all participants. Knowing that research is the basis for evidence-based medicine makes it obvious that interest in research and its results facilitates the understanding and application of evidence-based principles. In this sense, then, interest in research becomes paramount.

Research groups or, in a broader context, Departments and Surgery Services, increasingly need to act in an integrated manner in their research efforts, working in collaboration with other departments, services and medical schools. Senior researchers in surgery services should insist on encouraging the youngest and provide expertise in research design, study methodology, primary and secondary data collection, and complex data analysis, and work on the use of techniques to innovate and translate research results into real-world process of surgical activity. To support the vision of new surgeons, next generation research training is of paramount importance. It is perfectly feasible to associate care and research activities from medical residency to the battle for survival in working life. It is difficult but possible and it should be stimulated.

Surgery Services need to have as premises: VISION - leadership in the prevention and relief of human suffering due to surgical disease; MISSION - to advance the care of the surgical patient through multidisciplinary research, focused on results and to train the next generation of surgeons and researchers. VALUES - to develop a teaching culture combined with research in the hospital staff and in the faculty of the university surgical departments; to transform research innovation

1 - Full Professor, Department of Surgery, Federal University of Rio Grande do Norte, Brazil; Researcher PG2, CNPq. 
into improvement of procedures and surgical procedures; to ensure education and research in surgery for the next generation. These premises pass through ethics.

\section{Research in experimental surgery}

The laboratory of experimental surgery continues to be important and even indispensable in medical schools, a key factor in the evolution of surgery (since the time of Claude Bernard, Alfred Blalock and many others), both to test new surgical techniques, new materials and medications, and for surgical training and learning. The essential character of the laboratory of experimental surgery in medical schools has been increasingly important in the information technology century, for is high the speed with which new procedures, equipment and biocompatible materials for potential use in surgery are presented. The emergence of videoendoscopic surgery, robotics and other technologies has made it increasingly important to use experimental surgery laboratories to better understand the pathophysiological mechanisms of diseases, to undertake therapeutic trials with new drugs, to study biological markers and to evaluate these new techniques with perspectives of applicability in the human species ${ }^{1}$. All this has triggered, throughout history, ethical, bioethical, philosophical and religious reflections directed to research in vertebrate animals ${ }^{2}$.

\section{The use of animals in experimental surgery}

The use of laboratory animals in scientific research is a dilemma that has caused some of the greatest conflicts in bioethics debate. The principle of ethical experimentation with animals, known as the three Rs principle, proposes a reduction of the number of animals used in each experiment, refinement of experimental techniques to avoid unnecessary pain and suffering, and replacement by alternative methods whenever possible. Undoubtedly, this is a concern of experimental work advisors and academic surgeons, who have used technological refinements in the design of experimental models, resulting in a reduction in the number of animals and experimental groups. In this context, researchers should, before thinking about the real need for a biological model with animals, ensure the relevance of the study before deciding to propose a project involving animals. However, the reduction in the number of animals in surgical investigation should not compromise the detection and interpretation of biological effects and should not lead to the repetition of experiments. The design of the study and the calculation of the sample size, the control of variables, the statistical hypothesis tested, the choice of the statistical test used for data analysis and interpretation of the results contribute to refinement, enabling more information without increasing the number of animals used ${ }^{3}$.

\section{Ethics in the research}

Essentially, ethics in surgical research refers to the application of reasonable behavior to the best moral care with people and animals, as well as to the development and implementation of good laboratory practices in the detailed execution of experimental studies. To perform sound and acceptable surgical research, the surgeon researcher must adhere to the discipline ethic. Performed with the most appropriate scientific methodology available, good research involves a series of steps - the design of a project with the objective of answering the relevant question, the ideal care with the experimental subjects and the appropriate interpretation of data. The completion of these stages of surgical research allows science and ethics to collaborate intimately, resulting in better results. Brazil currently has its own legislation that establishes rules for research on human beings (Resolution 466/2012) and on animals (Law № 11,974/2008 and respective Normative Resolutions).

Without research, the many breakthroughs found in surgery would not have been possible the way we see them today. Research allows unprecedented information, more precise knowledge, elements of new and innovative discoveries and possibilities of better treatments. Without research we would not be able to help the thousands, millions of patients who have benefited so far from conquering the evolution of the diseases that affect them. Without research, stagnation in medicine and surgery would reign at 
all times. Patients and doctors would not have the same knowledge and possibilities in the treatment of diseases. Research, then, is essential to medicine in general and even more so for surgery. Discovery and validation are two of the most critical developments that emphasize the importance of research. Research can be considered the force that drives the innovators and discoverers who want to advance the understanding of the disease in the surgical world ${ }^{4}$.

\section{Developing ideas for new research in surgery}

Where do the research ideas come from? What are the factors that stimulate the research idea? When the neophyte researcher comes from a strictosensu graduate program and is driven by the interest in research and the multiplier effect of the know-how acquired, it is natural that in his home institution he be stimulated to develop studies in the same line of research of the advisor. Ideally, one should choose one or more lines of research, avoiding working in studies at random. Following a line, it is very likely that a paper will render the proposed question not completely answered, generating new questions and new chain searches. Those who are interested in this activity are always attentive to the questions not fully answered in the works they read, in the discussions in research forums, congresses in surgical area, discussions in formal rounds or informal meetings, where naturally arise new ideas and the viabilization of cooperation for further investigation. It is critical that an environment and research group be created in the surgery services or departments, which will be important in generating ideas and bringing them to light. It is an important, pleasurable activity that contributes to learning how to think and to generate knowledge ${ }^{5}$.

\section{REFERENCES}

1. Medeiros AC. Laboratório de cirurgia experimental. In: Saad Jr R, Salles RARV, Carvalho WR, Maia AM, editores. Tratado de Cirurgia do CBC. Rio de Janeiro: Atheneu; 2009. p. 1507-12.

2. Schanaider A, Silva PC. Uso de animais em cirurgia experimental. Acta Cir Bras. 2004;19(4):441-7.

\section{Writing and publishing results of research in surgery}

There is nothing more rewarding for the investigator than seeing the product of his/her research accepted for publication and published in an indexed journal. It is necessary to recognize the essential elements of research, to gather and report the data in a coherent and intelligent way, as critical elements in the submission for the success of the publication. Writing a research article is a demanding process that young surgeons are often ill-equipped to tackle, which is very natural and predictable. The help of more experienced researchers in the writing of scientific work is always important and welcome. It consists of many complex tasks and unavoidable difficulties that confront each researcher. Residence programs should give more attention to cultivating writing skills, especially in the scientific arena. Residency Programs oblige the residents to present a course completion work, which, if done with patient or animal data, must have been compulsorily approved by a Commission or Ethics in Research Committee, and by law publication of results is mandatory. Unfortunately, such works are rarely published. The Journal of the Brazilian College of Surgeons, currently with high international visibility, indexed in several national and international indexers, is available to all surgeons to disseminate their research.

Those who want to join surgical research groups in hospitals or experimental surgery labs must demonstrate not only that they can give good answers to relevant questions, but also that they can and should report their results clearly and effectively so they are useful for their peers.

3. Damy SB, Camargo RS, Chammas R, Figueiredo LF. [Fundamental aspects on animal research as applied to experimental surgery]. Rev Assoc Med Bras. 2010;56(1):103-11. Portuguese.

4. Toledo-Pereyra LH. Importance of medical and surgical research. J Invest Surg. 2009;22(5):325-6.

5. Toledo-Pereyra LH. Developing the research idea. J Invest Surg. 2011;24(3):101-2. 